\title{
Acute asthma exacerbations in emergency department
}

\author{
Domenico Lorenzo Urso ${ }^{1}$ \\ 1 Emergency Department Nicola Giannettasio Hospital, Rossano Calabro (CS) Italy
}

Asthma is an inflammatory disease of the airways. Acute exacerbations occur as part of the natural history of the disease due to airways irritants and treatment failure [1-4]. A substantial proportion of direct asthma costs result from the cost of treating acute asthma exacerbations [1]. Acute asthma is one of the most frequent reasons for attendance at the Emergency Department (ED) [3-4]. Despite international guidelines recommending appropriate therapy for acute asthma attacks, they are often poorly managed [1].

For practical purposes, an acute exacerbation can be generally defined as an acute or subacute episodes of progressively worsening shortness of breath, cough, wheezing, and chest tightness or some combination of these symptoms [1]. Exacerbations are characterized by decreases in expiratory airflow that can be documented and quantified by simple measurement of lung function (forced expiratory volume in 1 second [FEV1] or peak expiratory flow rate [PEFR]). The severity of asthma exacerbations ranges from mild to life-threatening. Early treatment of asthma exacerbations is the best strategy for management. Initial assessment should include a brief history, brief physical examination, and, for most patients, objective measures of lung function. FEV1 or PEFR to provide important information about the level of airflow obstruction both initially (Table I) and in response to treatment (Table II). The principal goals for treatment asthma exacerbations are:

1. Correction of significant hypoxemia, in moderate or severe exacerbations, by administering supplemental oxygen;

2. Rapid reversal of airflow obstruction by repetitive or continuous administration of a

\begin{tabular}{|lll|}
\hline Mild & \multicolumn{1}{c|}{$\begin{array}{c}\text { Symptoms } \\
\text { and signs }\end{array}$} & \multicolumn{1}{c|}{$\begin{array}{c}\text { Initial PEFR } \\
\text { (or FEV1) }\end{array}$} \\
Moderate & $\begin{array}{l}\text { Dyspnea only with } \\
\text { activity }\end{array}$ & $\begin{array}{l}\text { PEFR }>70 \% \text { predicted } \\
\text { Dyspnea interferes } \\
\text { or personal best }\end{array}$ \\
& $\begin{array}{l}\text { PEFR } 40-69 \% \text { predicted } \\
\text { activity }\end{array}$ \\
Severe & $\begin{array}{l}\text { Dyspnea at rest; } \\
\text { interferes with } \\
\text { conversation }\end{array}$ & PEFR $<40 \%$ predicted \\
Subset: life & $\begin{array}{l}\text { Too dyspneic to } \\
\text { speak; perspiring } \\
\text { threatening }\end{array}$ & PEFR $<25 \%$ predicted \\
\hline
\end{tabular}

Table I. Classifying severity of asthma exacerbations [4] 


\begin{tabular}{|ll|}
\hline Good response $\rightarrow$ Discharge home & FEV1 o PEFR $>70 \%$ \\
& - Response sustained 60 minutes after last treatment \\
& - No distress \\
& - Physical exam: normal \\
Incomplete Response $\rightarrow$ Admit to Hospital Ward & - FEV1 o PEFR $40-69 \%$ \\
& - Mild to moderate symptoms \\
Poor Response $\rightarrow$ Admit to Hospital Intensive Care & - FEV1 o PEFR $<40 \%$ \\
& - PCO2 $>42 \mathrm{mmHg}$ \\
& - Physical exam: symptoms severe, drowsiness, confusion
\end{tabular}

Table II. Repeat assessment acute exacerbations of asthma [4]

short acting beta-2 agonist (SABA) and, early in the course of treatment, administration of corticosteroids (CS) to patients who have moderate or severe exacerbations or to patients who fail to respond promptly and completely to SABA treatment;

3. Reduction of the likelihood of relapse of the exacerbation or future recurrence of severe airflow obstruction by intensifying therapy.

The response to initial treatment in the ED is a better predictor of the need for hospitalization than is the severity of an exacerbation on presentation.

\section{References}

1. Global Strategy for Asthma Management and Prevention, Global Initiative for Asthma (GINA) 2010. Available at: http://www.ginasthma.org (Last accessed September 2015)

2. Rodrigo C, Hall JB. Acute asthma in adults: a review. Chest 2004; 125: 1081-102

3. Lazarus SC. Emergency treatment of asthma. N Engl J Med 2010; 363: 755-64; http://dx.doi. org/10.1056/NEJMcp1003469

4. Urso DL. Treatment for acute asthma in the Emergency Department: practical aspects. Eur Rev Med Pharmacol Sci 2010; 14: 209-214 